\title{
INFLUENCE OF POLYGLYCEROL ESTER ADDITIVE ON PALM OIL FRACTIONATION IN RELATION TO THE CRYSTAL SIZE DISTRIBUTION
}

\section{SAW, M H*; ELINA HISHAMUDDIN*; SITI HAZIRAH MOHAMAD FAUZI*; YEOH, C B* and LIM, W H $^{*}$}

\begin{abstract}
The effect of polyglycerol ester (PGEmix-8) additive on palm oil fractionation was studied at isothermal temperature of $24^{\circ} \mathrm{C}$. Sampling was conducted at 20 min intervals to determine the solid fat content (SFC) of the slurries and the yield and compositions of the olein and stearin fractions. The peak of crystal size distribution was reduced from $100 \mu \mathrm{m}$ to an average of $70 \mu \mathrm{m}$ when $0.1 \%$ ( $w / w)$ to $0.5 \%$ ( $w / w)$ of PGEmix-8 were added in palm oil. The peak value was further reduced to $35 \mu \mathrm{m}$ when $0.7 \%$ (w/w) additive was used. In spite of this, the SFC of the slurries remained unchanged during the isothermal crystallisation. These results show that PGEmix-8 had influenced the crystal size distribution without affecting the volume of the crystals formed. The fractionation results showed that olein yield increased about $3 \%$ to $6 \%$ but the triacylglycerol composition of the oleins were comparable with the control. An increase of saturation and a reduction of monounsaturation content in the stearin fractions were observed with increasing PGEmix-8 addition. These results implied that the increase in olein yield was due to less olein entrainment as a result of the more homogeneous and smaller crystals of the palm oil slurries.
\end{abstract}

Keywords: palm oil crystallisation, polyglycerol esters, fractionation, FBRM.

Date received: 3 October 2018; Sent for revision: 4 October 2018; Accepted: 13 January 2019.

\section{INTRODUCTION}

Fractionation is an important process for the palm oil industry due to its composition of having almost equal amounts of saturated and unsaturated fatty acids. Palm oil is semi-solid in tropical climates, allowing it to separate into a low melting fraction olein and a high melting fraction - stearin (Deffense, 1985). The common techniques used for fractionation are fractional crystallisation, short-path distillation, fractional distillation, supercritical fluid extraction, liquid-liquid extraction, adsorption and membrane separation (Kellens et al., 2007). Fractional

Malaysian Palm Oil Board, 6 Persiaran Institusi, Bandar Baru Bangi, 43000 Kajang, Selangor, Malaysia. E-mail: meihuey@mpob.gov.my crystallisation is the process used for separating oils and fats into two or more components in the oils and fats industry which involves two steps; selective crystallisation and filtration. Dry fractionation is relatively simple and cost-effective process, thus, it is commonly used in most palm oil refineries. It is a dry process using direct filtration of triacylglycerol (TAG) crystals after a controlled and programmed cooling step, which does not involve the use of any chemicals (Kellens et al., 2007). This process has an advantage of minimum product losses because no effluent is produced during the process (Kellens et al., 2007). In dry fractionation, the molten feed is partially crystallised to the desired fractionation temperature by a programmed controlled cooling, holding for crystals growth, and filtration by membrane filter press (Gunstone, 2001). 
Latest development in palm oil fractionation are focusing on areas related to crystallisation and solidliquid separation. The use of crystallisation additive is one of the interesting areas of development in palm oil fractionation, other than the modification of the crystalliser and the filtration system (Saw et al., 2015). Crystallisation additives may change the crystal size distribution of the palm oil slurry, hence, varying the quality and yield of the products. These additives may influence the nucleation, crystal growth, morphology, heat capacity, rheology and polymorphic stability during crystallisation of oils and fats (Smith et al., 2011). Early research on the effect of minor components such as free fatty acids (FFA) and diacylglycerol (DAG) on palm oil crystallisation was conducted by Jacobsberg et al. (1976). His team concluded that palm oil fractionation is adversely influenced by the increase in the FFA and DAG content, as well as the degree of oxidation. Verstringe et al. (2013) reported that earlier onset of crystallisation occurred when monopalmitin was added during palm oil crystallisation, which suggested a nucleation promotion effect by the additive. Further studies on the template effect of the monopalmitin during palm oil crystallisation indicated that the additive promoted palm oil crystallisation and the crystal formation is oriented by the previously crystallised monopalmitin during the nucleation step (Verstringe et al., 2014). A similar observation was reported by Basso et al. (2010), whereby tripalmitin increases crystallisation rate of palm oil and formed larger crystals by crystallising with the tripalmitin from palm oil due to its high concentration in palm oil (Basso et al., 2010). These studies indicated that the additives containing palmitic acid moieties such as monopalmitin and tripalmitin are showing seeding effects in enhancing palm oil crystallisation. De Oliveira et al. (2014) claimed that low concentration of DAG of $6.0 \%$ to $8.5 \%$ increased the crystallisation rate of palm oil. However, Saberi et al. (2011) found that 5\% of palm-based DAG reduced the rates of nucleation and crystal growth of palm oil. When $30 \%$ and $50 \%$ of DAG was blended with palm oil, the induction time was reduced with the increase of the Avrami constant $(k)$, implying that high concentration of DAG promoted nucleation and crystallisation rates in palm oil (Saberi et al., 2011).

In our previous study, the influence of polyglycerol esters (PGEmix-8) additive on palm oil isothermal crystallisation was studied using Focused Beam Reflectance Measurement (FBRM) and Differential Scanning Calorimeter (DSC) (Saw et al., 2017). The study showed that $0.7 \%$ (w/w) PGEmix-8 promotes nucleation by creating additional heterogeneous nuclei. The study concluded that the additive greatly affected the crystal size distribution during palm oil crystallisation, leading to the formation of a huge quantity of smaller and more even sized crystals as compared to the control (Saw et al., 2017). Such changes in crystal size distribution may affect the fractionation process of palm oil. Thus, in this article, the crystal size distribution of the palm oil slurries before the filtration was measured, with and without the use of the additives. The relationship of crystallisation size distribution to palm oil fractionation was investigated in terms of the olein yield and the composition of the fractionation products, i.e. the respective olein and the stearin fractions. The changes of solid fat content (SFC) during the isothermal crystallisation were also monitored.

\section{MATERIALS AND METHODS}

\section{Materials}

Refined, bleached and deodourised palm oil (RBDPO) was purchased from MOI Foods Malaysia Sdn Bhd (Selangor, Malaysia), whereas the PGEmix-8 was obtained from Sakamoto Yakuhin Kogyo Co. Ltd (Osaka, Japan). The additive consists of a mixture of fatty acids of palmitic acid, stearic acid and oleic acid, with a melting point of $42.8^{\circ} \mathrm{C}$ (Kuriyama et al., 2011).

\section{Isothermal Crystallisation of Palm Oil with PGEmix-8 Additives: Crystal Size Distribution by FBRM}

Crystal size distribution of palm oil with the addition of PGEmix-8 additives were recorded using a Lasentec D600L probe (Schwerzenbach, Switzerland) in a 1 litre stirred glass Mettler Toledo Labmax reactor (Normah, 2013). The control run for this study was the crystallisation of palm oil without the use of any additive. The concentrations of PGEmix- 8 additive used were $0.1 \%(\mathrm{w} / \mathrm{w}), 0.3 \%$ $(\mathrm{w} / \mathrm{w}), 0.5 \%(\mathrm{w} / \mathrm{w})$ and $0.7 \%(\mathrm{w} / \mathrm{w})$. Firstly, $700 \mathrm{~g}$ of $\mathrm{RBDPO}$ and the additive was loaded into the reactor that was equipped with a glass anchor agitator, stirred at a rate of $30 \mathrm{rpm}$. The same temperature program as the previous study was applied in this study (Saw et al., 2017). The oil mixture was first heated to $70^{\circ} \mathrm{C}$ to fully melt and homogenise the additive and the oil. The melt was then cooled down slowly to $24^{\circ} \mathrm{C}$ and held at this temperature for $120 \mathrm{~min}$. The data on the crystal size distribution was collected using a 90 log-channel over the size range of 1-1000 $\mu \mathrm{m}$. The chord length distribution of the palm oil slurries was measured at the end of the isothermal run to determine the distribution of crystal size right before filtration.

\section{SFC during the Isothermal Crystallisation}

Samples were collected at 20 min intervals to determine the SFC of the palm oil slurries across the 
$120 \mathrm{~min}$ isothermal crystallisation time. Minispec pulsed nuclear magnetic resonance, mq20 (Bruker, Germany) was used to perform this analysis.

\section{Dry Fractionation of Palm Oil with PGEmix-8 Additive}

After the isothermal crystallisation for $120 \mathrm{~min}$, the slurry samples were filtered and the weights of olein and stearin fractions were recorded. The olein and stearin fractions were analysed for their fatty acid and TAG composition. Olein yield was calculated based on the total weight of the olein and stearin fractions.

\section{Analysis of Fractionation Products}

TAG composition. TAG composition of the samples was determined by using Agilent 1100 Series reversed-phase high performance liquid chromatography (HPLC) from Agilent Technologies (Waldbronn, Germany), equipped with a refractive index detector and a Lichrospher ${ }^{\circledR} 100$ RP-18 column, $250 \mathrm{~mm} \times 4.6 \mathrm{~mm}$ with $5 \mu \mathrm{m}$ particle size (Darmstadt, Germany). The oil samples were weighed and diluted in acetone for injection into the HPLC column. The mobile phase used was a pre-mixed acetone and acetonitrile with a ratio of 3:1. The flow rate for the mobile phase was $1 \mathrm{ml}$ $\mathrm{min}^{-1}$. Identification of the TAG peaks was based on reference material - RBD palm oil and comparison with the literatures by Ghazali et al. (1995) and Swe et al. (1995). The most abundant TAG in RBD palm oil are palmitic-oleic-oleic (POO) and palmitic-oleicpalmitic (POP). The term of POP refers to mixture of POP and trace amount of PPO as these isomers cannot be separated using this method.

Fatty acid composition (FAC). Fatty acid methyl ester (FAME) for the FA composition analyses were prepared by referring to MPOB Test Methods p3.4Part 4 (2005). A 430-GC gas chromatography (Bruker, Germany) fitted with a Flame Ionisation Detector (FID) was used to analyse the FAME. One $\mu \mathrm{l}$ of the sample was injected into SGE BPX70 column with dimension of $60 \mathrm{~m} \times 0.25 \mathrm{~mm} \times 0.25 \mu \mathrm{m}$.

Hydrogen with air in a ratio of 1:100 was used as the carrier gas with a flow rate of $0.8 \mathrm{ml} \mathrm{min}{ }^{-1}$. The detector and injector temperatures were set at $200^{\circ} \mathrm{C}$ and $140^{\circ} \mathrm{C}$, respectively. The separation of FAME was performed under isothermal condition at $185^{\circ} \mathrm{C}$. FAME mix RM6 from Supelco was used as the standard material for identification and quantification of the FAME moieties.

\section{Statistical Analysis}

The olein yield, TAG composition and FAC of the olein and stearin fractions were analysed using the analysis of variance (ANOVA) to determine the significance of the additive dosage on the palm oil dry fractionation during the isothermal crystallisation (120 $\mathrm{min}$ ) at 95\% confident level, in which a $p$-value of 0.05 is considered as statistically significant. The software used was Minitab 16.2. Comparisons were made using Tukey post-hoc test.

\section{RESULTS AND DISCUSSION}

\section{Effect of PGEmix-8 on Chord Length Distribution}

The effect of PGEmix-8 on palm oil crystallisation was studied in the previous article (Saw et al., 2017). The article concluded that PGEmix- 8 additive greatly affected crystallisation of palm oil by enhancing nucleation and retarding crystal growth, which resulted in the formation of smaller and even size crystals (Saw et al., 2017). In this study, the chord length distribution of palm oil slurries at the end of isothermal crystallisation before final filtration was measured using FBRM as shown in Figure 1. FBRM is an effective technique in monitoring particle characteristics within different physical or chemical processes in agitated crystallisation system which ensures real time in situ monitoring of the particle size in the system (Hishamuddin et al., 2011; 2016). The data on the final crystal size distribution of the palm oil slurry in the crystalliser allows us to understand the actual situation in the system before the filtration step which can be related to the fractionation process.

The results showed that the crystal populations were slightly shifted to the lower chord length region, whereby the average crystal size was reduced from $100 \mu \mathrm{m}$ to $80 \mu \mathrm{m}, 73 \mu \mathrm{m}$ and $70 \mu \mathrm{m}$ when $0.1 \%(\mathrm{w} / \mathrm{w}), 0.3 \%(\mathrm{w} / \mathrm{w})$ and $0.5 \%(\mathrm{w} / \mathrm{w})$ of PGEmix-8 were added, respectively. A more obvious change was observed when $0.7 \%(\mathrm{w} / \mathrm{w})$ of PGEmix-8 was used. The crystal population became very much steeper at $0.7 \%(\mathrm{w} / \mathrm{w})$ and was shifted more to the lower chord length region. The size was further reduced by half to about $35 \mu \mathrm{m}$ when $0.7 \%$ $(\mathrm{w} / \mathrm{w})$ of the additive was used. Furthermore, the number of crystals with crystal sizes larger than $100 \mu \mathrm{m}$ were significantly reduced as compared to the control. For instance, the number of crystals with a size of $100 \mu \mathrm{m}$ was reduced from 171 counts in the control to 140 count when $0.1 \%(\mathrm{w} / \mathrm{w})$ to $0.5 \%(\mathrm{w} / \mathrm{w})$ of PGEmix-8 were used, and further dropped drastically to 38 count when $0.7 \%(\mathrm{w} / \mathrm{w})$ of the additive was used. For crystals with a size of $200 \mu \mathrm{m}$, the numbers were reduced from 52 counts in the control to about 30 counts when $0.1 \%(\mathrm{w} / \mathrm{w})$ to $0.5 \%(\mathrm{w} / \mathrm{w})$ of the additive were added. Almost negligible amount of large crystals with the size of more than $150 \mu \mathrm{m}$ were detected when $0.7 \%(\mathrm{w} / \mathrm{w})$ additive was used. These results indicate that the 


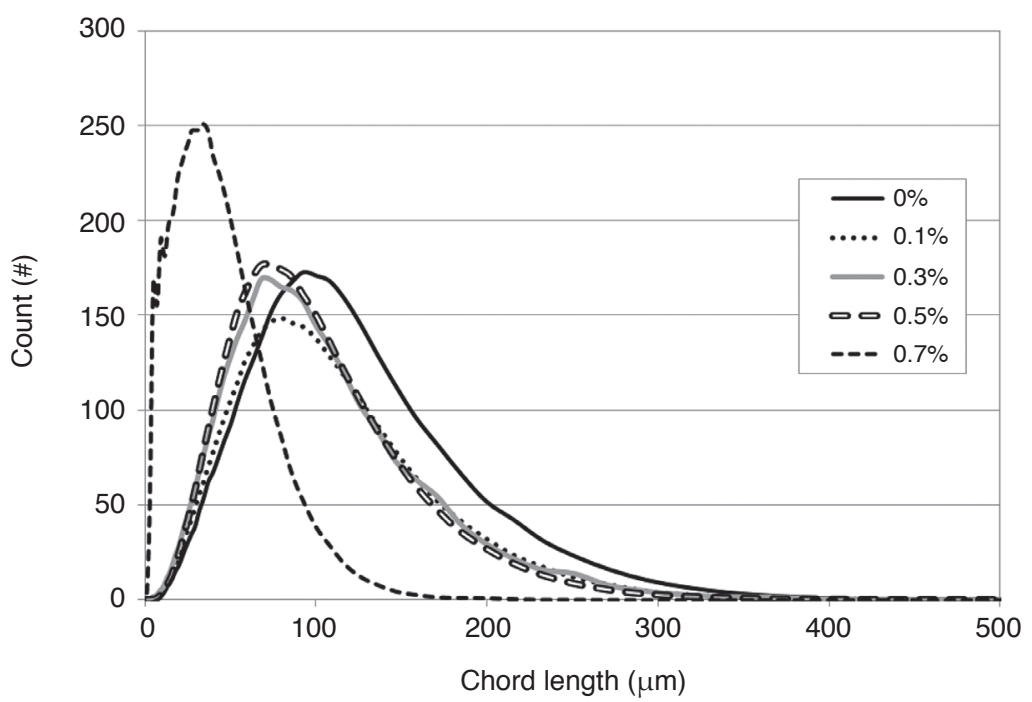

Figure 1. Chord length distribution of palm oil slurries with and without the polyglycerol ester additive (PGEmix-8) at the end of isothermal crystallisation at $24^{\circ} \mathrm{C}$.

overall crystal size distribution when $0.7 \%(\mathrm{w} / \mathrm{w})$ additive was used was much smaller than the crystal size population of the control.

This occurrence can be explained by a schematic diagram shown in Figure 2 which illustrates the possible mechanism of interaction of PGEmix-8 molecules with palm oil molecules during the crystallisation. When a sufficient amount of PGEmix-8 additive was added, a greater heterogeneous nucleation occurred. The additive molecules acted as foreign material for the formation of clusters and this resulted in the production of more nuclei (Sato et al., 1999). During the crystal growth stage, the PGEmix- 8 molecules retard the crystal growth by blocking the molecule packing, which prevents the crystals from growing and agglomerating into bigger crystals (Saw et al., 2017). Smith et al. (2018) explained that retardation could happen when minor components or additive molecules block the adsorption of lipid molecules at the kink site on a growing crystal surface, thus retarding the crystal growth. A different retardation mechanism of polyglycerol fatty acid esters (PGFE) in DAG oil was reported by Saitou et al. (2017). According to their study, the retardation was caused by the formation of liquid-crystal like supramolecular complex structures made up of the high-melting fractions of DAG and PGFE molecules.

Although the additive has shown an important role in affecting the crystallisation and crystal size distribution of palm oil, the SFC of the slurries were found to remain at a similar level as the control during the isothermal crystallisation (Figure 3). This indicates that the additive had changed the crystal size distribution but did not affect the volume or the amount of the crystallisation under the same crystallisation conditions. A similar observation was reported by Basso et al. (2010), where

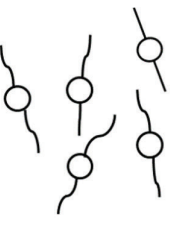

Fat molecules

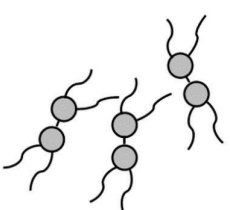

PGEmix-8 molecules

Cluster formation
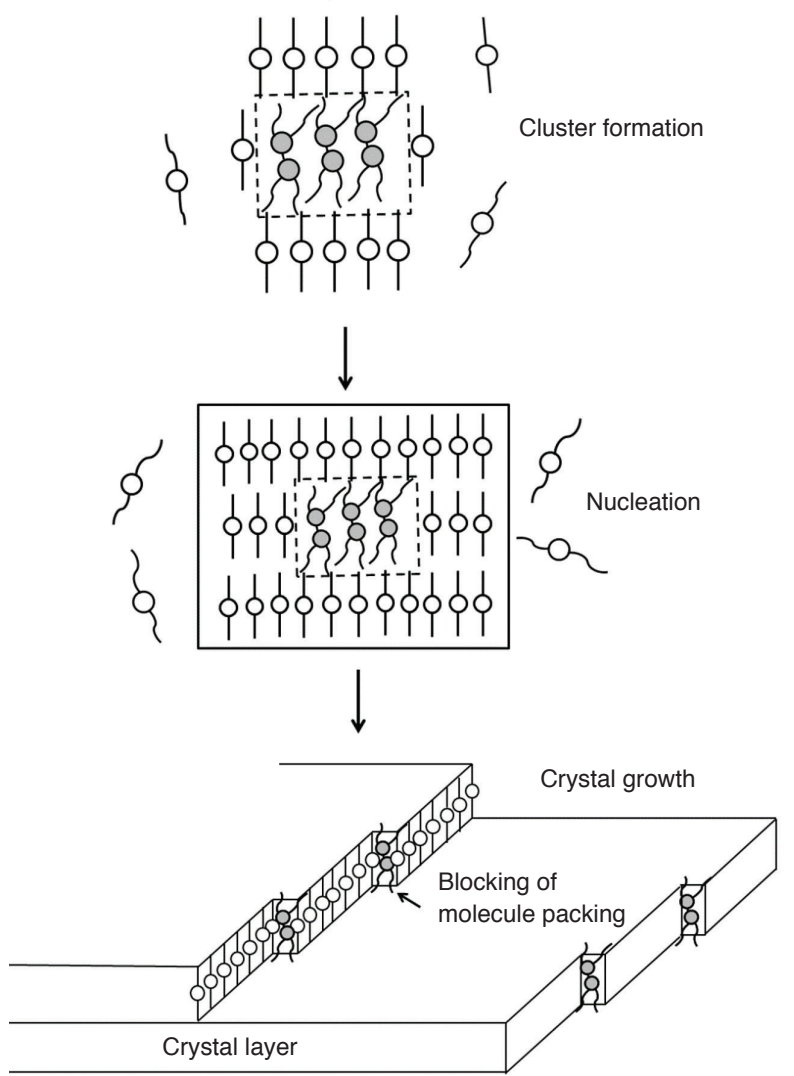

Source: Saw et al. (2017).

Figure 2. Schematic diagram of the possible mechanism and interaction of the polyglycerol ester (PGEmix-8) additive molecules with palm oil molecules. 


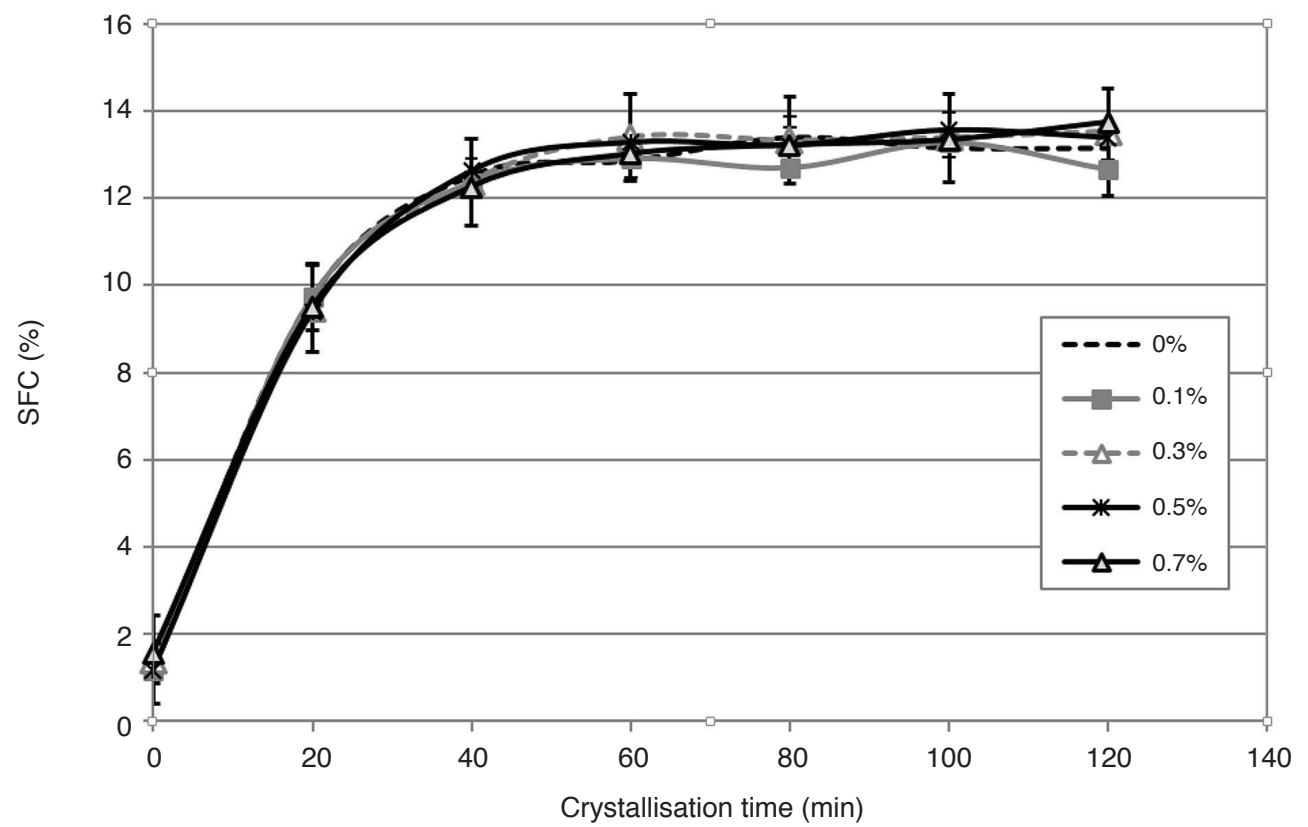

Figure 3. Solid fat contents (SFC) of palm oil slurry during isothermal crystallisation at $24^{\circ} \mathrm{C}$ for the control and those with $0.1 \%(w / w), 0.3 \%$ $(w / w), 0.5 \%(w / w)$ and $0.7 \%(w / w)$ of the polyglycerol ester additive (PGEmix-8).

monoacylglycerol additive increased the number of nuclei, accelerated the process of crystal formation, and lead to the formation of smaller crystals without changing the final solid content during palm oil crystallisation. The combination of FBRM and SFC results revealed that the blocking effect of the PGEmix-8 molecules on the crystal growth sites only prevented the formation of large crystals but did not affect the total volume of crystallisation as a whole. In other words, more number of crystals with smaller and more uniform size were formed instead of the formation of larger crystals with a wider size range.

\section{Fractionation: Effect of PGEmix-8 on Olein Yield}

According to Timms (2005), the composition of the olein only relies on the crystallisation step, while the composition of the stearin fraction depends on both the crystallisation and separation steps. Therefore, the changes in crystal size distribution of palm oil by the additive is believed to have some effects on the fractionation process. Figure 4 shows the olein yield of palm oil fractionation with different dosages of PGEmix-8 additive. A comparison using the Tukey test showed that palm olein yield increased significantly from $59.4 \%$ to $62.1 \%$ when $0.1 \%(\mathrm{w} / \mathrm{w})$ PGEmix-8 was used and further increased to $65.0 \%$ when $0.7 \%(\mathrm{w} / \mathrm{w})$ of the additive were used. The increase in olein yield was higher with increasing addition of PGEmix-8. These results indicate that PGEmix-8 had effectively increased the olein yield, even with the addition of $0.1 \%(\mathrm{w} / \mathrm{w})$ PGEmix-8. The increase of olein yield could be either due to incomplete crystallisation or more efficient filtration caused by the additive. Insufficient crystallisation could happen because of the inhibitory effects of the additive in crystal growth as discussed in Figure 2. If this happens, fewer crystals will be formed, causing the increase of the saturation content in the olein, as some saturation components will still remain in the liquid fraction after filtration. On the other hand, the olein yield can also be increased if the filtration is more efficient due to the more homogeneous crystal size distribution. To verify the cause of the olein increment, the olein and stearin fractions were further analysed for their TAG composition and FAC.

\section{Fractionation: Effect of PGEmix-8 on Olein and} Stearin Composition

Table 1 shows the comparison of acylglycerol composition of the final oleins. The acylglycerol compositions of all oleins obtained with different PGEmix-8 amounts were similar and comparable. Statistical analysis with Tukey test showed that the total DAG, triunsaturated TAG, diunsaturated TAG, disaturated TAG and trisaturated TAG were all insignificantly different as compared to the control. A very slight increase in the total triunsaturated and trisaturated TAG were observed, however, the difference was statistically insignificant. This shows that the increase in olein yield was unlikely caused by insufficient crystallisation, but instead could have been due to the improvement in the filtration efficiency caused by a more homogeneous crystal size distribution.

Table 2 shows the effects of the additives on the FAC composition of the final oleins which are categorised 


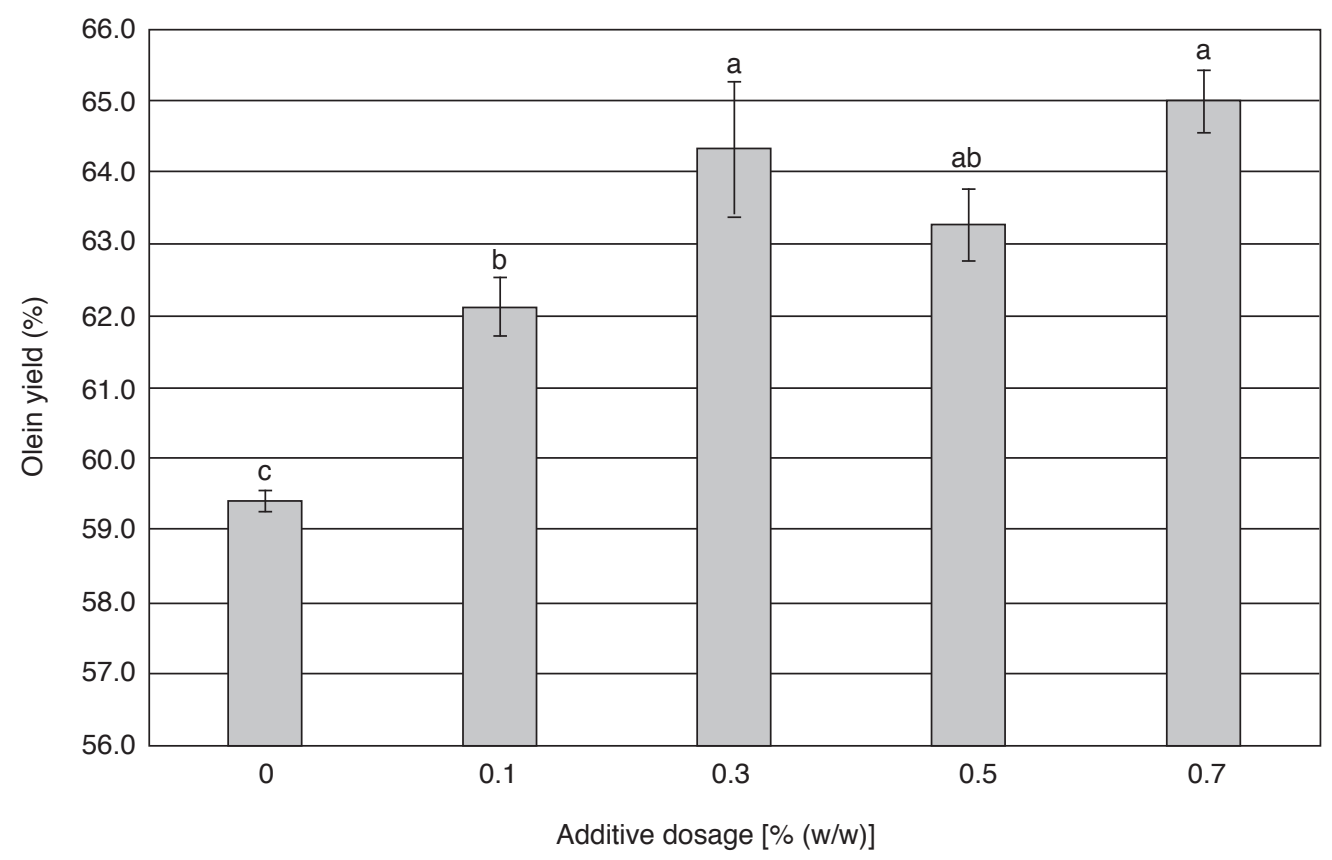

Note: Significance testing was conducted between different levels of the PGEmix-8 dosage. Different letters indicate significant differences at $p<0.05$ according to Tukey's test.

Figure 4. Olein yields of laboratory scale fractionation with different dosages of the polyglycerol ester (PGEmix-8) additive.

TABLE 1. COMPARISON OF THE ACYLGLYCEROL COMPOSITION OF FINAL OLEINS WITH DIFFERENT DOSAGES OF POLYGLYCEROL ESTER (PGEmix-8) ADDITIVES

\begin{tabular}{|c|c|c|c|c|c|}
\hline \multirow{2}{*}{ Acylglycerol (area \%) } & \multicolumn{5}{|c|}{ Dosage of PGEmix-8 (\%) } \\
\hline & 0.0 & 0.1 & 0.3 & 0.5 & 0.7 \\
\hline Total DAG & $6.4 \pm 0.0^{\mathrm{a}}$ & $6.2 \pm 0.2^{\mathrm{a}}$ & $6.2 \pm 0.1^{\mathrm{a}}$ & $6.1 \pm 0.0^{\mathrm{a}}$ & $6.1 \pm 0.1^{\mathrm{a}}$ \\
\hline OLL & $0.4 \pm 0.0^{\mathrm{a}}$ & $0.5 \pm 0.1^{\mathrm{a}}$ & $0.5 \pm 0.0^{\mathrm{a}}$ & $0.5 \pm 0.0^{\mathrm{a}}$ & $0.5 \pm 0.0^{\mathrm{a}}$ \\
\hline OLO & $2.0 \pm 0.1^{\mathrm{a}}$ & $2.1 \pm 0.1^{\mathrm{a}}$ & $2.1 \pm 0.1^{\mathrm{a}}$ & $2.1 \pm 0.1^{\mathrm{a}}$ & $2.1 \pm 0.0^{\mathrm{a}}$ \\
\hline OOO & $5.3 \pm 0.1^{\mathrm{a}}$ & $5.2 \pm 0.1^{\mathrm{a}}$ & $5.2 \pm 0.0^{\mathrm{a}}$ & $5.2 \pm 0.0^{\mathrm{a}}$ & $5.3 \pm 0.2^{\mathrm{a}}$ \\
\hline Triunsaturated TAG & $7.7 \pm 0.1^{\mathrm{a}}$ & $7.8 \pm 0.2^{\mathrm{a}}$ & $7.8 \pm 0.0^{\mathrm{a}}$ & $7.8 \pm 0.1^{\mathrm{a}}$ & $7.8 \pm 0.2^{\mathrm{a}}$ \\
\hline PLL & $2.4 \pm 0.0^{\mathrm{a}}$ & $2.4 \pm 0.1^{\mathrm{a}}$ & $2.5 \pm 0.0^{\mathrm{a}}$ & $2.5 \pm 0.1^{\mathrm{a}}$ & $2.4 \pm 0.0^{\mathrm{a}}$ \\
\hline PLO & $10.3 \pm 0.0^{\mathrm{a}}$ & $10.4 \pm 0.0^{\mathrm{a}}$ & $10.3 \pm 0.0^{\mathrm{a}}$ & $10.2 \pm 0.1^{\mathrm{a}}$ & $10.3 \pm 0.0^{\mathrm{a}}$ \\
\hline POO & $26.7 \pm 0.1^{\mathrm{a}}$ & $26.8 \pm 0.4^{\mathrm{a}}$ & $26.4 \pm 0.2^{\mathrm{a}}$ & $26.4 \pm 0.1^{\mathrm{a}}$ & $26.6 \pm 0.0^{\mathrm{a}}$ \\
\hline SOO & $3.1 \pm 0.2^{\mathrm{a}}$ & $3.3 \pm 0.3^{\mathrm{a}}$ & $3.5 \pm 0.0^{\mathrm{a}}$ & $3.2 \pm 0.0^{\mathrm{a}}$ & $3.3 \pm 0.1^{\mathrm{a}}$ \\
\hline Diunsaturated TAG & $42.5 \pm 0.2^{\mathrm{a}}$ & $42.9 \pm 0.1^{\mathrm{a}}$ & $42.7 \pm 0.2^{\mathrm{a}}$ & $42.4 \pm 0.1^{\mathrm{a}}$ & $42.5 \pm 0.0^{\mathrm{a}}$ \\
\hline MLP & $0.6 \pm 0.0^{\mathrm{a}}$ & $0.6 \pm 0.1^{\mathrm{a}}$ & $0.7 \pm 0.1^{\mathrm{a}}$ & $0.7 \pm 0.1^{\mathrm{a}}$ & $0.6 \pm 0.0^{\mathrm{a}}$ \\
\hline PLP & $9.8 \pm 0.2^{\mathrm{a}}$ & $9.5 \pm 0.1^{\mathrm{a}}$ & $9.5 \pm 0.0^{\mathrm{a}}$ & $9.5 \pm 0.1^{\mathrm{a}}$ & $9.6 \pm 0.1^{\mathrm{a}}$ \\
\hline POP & $26.8 \pm 0.1^{\mathrm{a}}$ & $26.8 \pm 0.3^{\mathrm{a}}$ & $26.5 \pm 0.3^{\mathrm{a}}$ & $26.8 \pm 0.1^{\mathrm{a}}$ & $26.8 \pm 0.0^{\mathrm{a}}$ \\
\hline POS & $4.8 \pm 0.1^{\mathrm{a}}$ & $4.8 \pm 0.1^{\mathrm{a}}$ & $5.0 \pm 0.1^{\mathrm{a}}$ & $4.9 \pm 0.0^{\mathrm{a}}$ & $5.0 \pm 0.1^{\mathrm{a}}$ \\
\hline SOS & $0.7 \pm 0.1^{\mathrm{a}}$ & $0.7 \pm 0.1^{\mathrm{a}}$ & $0.7 \pm 0.0^{\mathrm{a}}$ & $0.9 \pm 0.3^{\mathrm{a}}$ & $0.6 \pm 0.0^{\mathrm{a}}$ \\
\hline Disaturated TAG & $42.6 \pm 0.1^{\mathrm{ab}}$ & $42.4 \pm 0.0^{\mathrm{ab}}$ & $42.3 \pm 0.1^{\mathrm{b}}$ & $42.7 \pm 0.1^{\mathrm{a}}$ & $42.5 \pm 0.0^{\mathrm{ab}}$ \\
\hline PPP & $0.5 \pm 0.1^{\mathrm{a}}$ & $0.6 \pm 0.2^{\mathrm{a}}$ & $0.6 \pm 0.0^{\mathrm{a}}$ & $0.7 \pm 0.0^{\mathrm{a}}$ & $0.5 \pm 0.1^{\mathrm{a}}$ \\
\hline PPS & $0.0 \pm 0.0^{\mathrm{a}}$ & $0.0 \pm 0.0^{\mathrm{a}}$ & $0.1 \pm 0.1^{\mathrm{a}}$ & $0.1 \pm 0.1^{\mathrm{a}}$ & $0.3 \pm 0.2^{\mathrm{a}}$ \\
\hline Trisaturated TAG & $0.5 \pm 0.1^{\mathrm{a}}$ & $0.6 \pm 0.2^{\mathrm{a}}$ & $0.8 \pm 0.2^{\mathrm{a}}$ & $0.7 \pm 0.1^{\mathrm{a}}$ & $0.8 \pm 0.0^{\mathrm{a}}$ \\
\hline
\end{tabular}

Note: Significance testing was conducted between different levels of PGEmix-8 dosage. Different letters indicate significant differences at $p<0.05$ according to Tukey's test.

TAG - triacyglycerol; DAG - diacylglycerol; Triunsaturated TAG - OLL, OLO, OOO; Diunsaturated TAG - PLL, PLO, POO, SOO; Disaturated TAG - MLP, PLP, POP, POS, SOS; Trisaturated TAG - PPP, PPS; O - oleic acid; L - linoleic acid; P - palmitic acid; $S$ - stearic acid. 
TABLE 2. COMPARISON OF THE FREE FATTY ACID (FFA) OF THE FINAL OLEINS PRODUCED WITH DIFFERENT AMOUNTS OF POLYGLYCEROL ESTER (PGEmix-8) ADDITIVE

\begin{tabular}{|c|c|c|c|c|c|}
\hline \multirow{2}{*}{$\begin{array}{c}\text { Fatty acid composition } \\
(\text { area } \%)\end{array}$} & \multicolumn{5}{|c|}{ Dosage of PGEmix-8 (\%) } \\
\hline & 0.0 & 0.1 & 0.3 & 0.5 & 0.7 \\
\hline C12:0 & $0.2 \pm 0.0^{\mathrm{a}}$ & $0.2 \pm 0.0^{\mathrm{a}}$ & $0.2 \pm 0.0^{\mathrm{a}}$ & $0.2 \pm 0.0^{\mathrm{a}}$ & $0.2 \pm 0.0^{\mathrm{a}}$ \\
\hline C14:0 & $1.0 \pm 0.0^{\mathrm{a}}$ & $0.9 \pm 0.0^{b}$ & $0.9 \pm 0.0^{b}$ & $0.9 \pm 0.0^{\mathrm{b}}$ & $1.0 \pm 0.0^{\mathrm{a}}$ \\
\hline C16:0 & $39.7 \pm 0.1^{\mathrm{a}}$ & $39.5 \pm 0.1^{\mathrm{ab}}$ & $39.4 \pm 0.0^{\mathrm{b}}$ & $39.5 \pm 0.0^{\mathrm{ab}}$ & $39.6 \pm 0.1^{\mathrm{ab}}$ \\
\hline C18:0 & $4.0 \pm 0.0^{\mathrm{e}}$ & $4.1 \pm 0.0^{\mathrm{d}}$ & $4.1 \pm 0.0^{c}$ & $4.1 \pm 0.0^{\mathrm{b}}$ & $4.2 \pm 0.0^{\mathrm{a}}$ \\
\hline C20:0 & $0.4 \pm 0.0^{\mathrm{a}}$ & $0.4 \pm 0.0^{\mathrm{a}}$ & $0.4 \pm 0.0^{\mathrm{a}}$ & $0.4 \pm 0.0^{\mathrm{a}}$ & $0.4 \pm 0.0^{\mathrm{a}}$ \\
\hline SFA & $45.3 \pm 0.1^{\mathrm{ab}}$ & $45.1 \pm 0.1^{\mathrm{ab}}$ & $45.0 \pm 0.0^{\mathrm{b}}$ & $45.1 \pm 0.0^{\mathrm{ab}}$ & $45.4 \pm 0.1^{\mathrm{a}}$ \\
\hline C16:1 & $0.2 \pm 0.0^{\mathrm{a}}$ & $0.2 \pm 0.0^{\mathrm{a}}$ & $0.2 \pm 0.0^{\mathrm{a}}$ & $0.2 \pm 0.0^{\mathrm{a}}$ & $0.2 \pm 0.0^{\mathrm{a}}$ \\
\hline C18:1 & $44.1 \pm 0.0^{\mathrm{a}}$ & $44.1 \pm 0.0^{\mathrm{a}}$ & $43.9 \pm 0.0^{\mathrm{ab}}$ & $43.9 \pm 0.0^{\mathrm{ab}}$ & $43.8 \pm 0.1^{\mathrm{b}}$ \\
\hline MUFA & $44.3 \pm 0.0^{\mathrm{a}}$ & $44.3 \pm 0.1^{\mathrm{a}}$ & $44.1 \pm 0.0^{\mathrm{a}}$ & $44.1 \pm 0.1^{\mathrm{a}}$ & $44.0 \pm 0.1^{\mathrm{a}}$ \\
\hline C18:2 & $10.1 \pm 0.1^{\mathrm{b}}$ & $10.3 \pm 0.0^{\mathrm{ab}}$ & $10.4 \pm 0.0^{\mathrm{a}}$ & $10.4 \pm 0.0^{\mathrm{a}}$ & $10.4 \pm 0.0^{\mathrm{a}}$ \\
\hline C18:3 & $0.3 \pm 0.0^{\mathrm{a}}$ & $0.3 \pm 0.0^{\mathrm{a}}$ & $0.3 \pm 0.0^{\mathrm{a}}$ & $0.3 \pm 0.0^{\mathrm{a}}$ & $0.3 \pm 0.0^{\mathrm{a}}$ \\
\hline PUFA & $10.4 \pm 0.1^{\mathrm{b}}$ & $10.6 \pm 0.0^{a b}$ & $10.7 \pm 0.0^{\mathrm{a}}$ & $10.7 \pm 0.1^{\mathrm{a}}$ & $10.7 \pm 0.1^{\mathrm{a}}$ \\
\hline
\end{tabular}

Note: Significance testing was conducted between different levels of PGEmix-8 dosage. Different letters indicate significant differences at $p<0.05$ according to Tukey's test.

SFA - saturated fatty acids (C12:0, C14:0, C16:0, C18:0 and C20:0); MUFA - monounsaturated fatty acids (C16:1 and C18:1); PUFA polyunsaturated fatty acids (C18:2 and C18:3).

into saturated fatty acid (SFA), monounsaturated fatty acid (MUFA) and polyunsaturated fatty acid (PUFA). As expected, a trend similar to the TAG composition was observed for the FAC. The FAC of oleins with the use of additives were similar to that of the control, except for total PUFA. A significant increase of PUFA was observed, which is contributed by the increase in linoleic acid (C18:2) from $10.1 \%$ to $10.4 \%$ with the use of different dosages of the additive $(p<0.05)$. As for MUFA, a slight reduction in oleic acid (C18:1) was observed, but the difference was again insignificant when $0.1 \%(\mathrm{w} / \mathrm{w})$ to $0.5 \%$ $(\mathrm{w} / \mathrm{w})$ of PGEmix-8 was used. However, when $0.7 \%(\mathrm{w} / \mathrm{w})$ of the additive was incorporated, $\mathrm{C} 18: 1$ was significantly reduced from $44.1 \%$ to $43.8 \%$. Although the total SFA was insignificantly different, a slight reduction in palmitic acid (C16:0) of $0.1 \%$ to $0.3 \%$ and a slight increase in stearic acid (C18:0) of $0.1 \%$ were observed in the SFA that balanced up the total SFA. It is believed that the PGEmix-8 additive slightly enhanced the crystallisation of TAG containing a higher amount of C16:0 compared to those with C18:0, further causing the slight reduction of C16:0 fatty acid in the olein fractions. Similar finding was reported by Shimamura et al. (2013), whereby the crystallisation of palm stearin was highly promoted when polyglycerine fatty acid esters with higher concentrations of palmitic acid moiety were added. The crystallisation promotion effect was reduced with the increasing concentration of oleic acid moiety in the polyglycerine fatty acid esters (Shimamura et al., 2013). Their findings can be related to our sutdy as palm oil and palm stearin contain TAG with high amounts of palmitic acid. In our case, it was found that the PGEmix-8 molecules have slightly higher affinity towards $\mathrm{C} 16: 0$ than C18:0 in the formation of crystals. This could be due to the composition of the PGEmix-8 having higher amounts of C16:0 than C18:0 moieties. Thus, more TAG containing C16:0 was removed as crystals during the fractionation which resulted in the slight reduction of $\mathrm{C} 16: 0$ in the olein fractions.

Unlike the olein fractions, the effect of PGEmix-8 additive on FAC of the stearin fractions were very significant especially for SFA and MUFA. Figure 5 shows the total FAC of the stearin fractions with the use of PGEmix-8 additives. The total SFA significantly increased even with the lowest dosage of $0.1 \%(\mathrm{w} / \mathrm{w})$ PGEmix- 8 . The total MUFA was reduced significantly when more than $0.3 \%(\mathrm{w} / \mathrm{w})$ of PGEmix-8 was used in the fractionation process. The total PUFA content remained unchanged for all the stearins. Moreover, the increase of olein yield also implies a reduction in stearin yield. This indicated that lesser amounts of stearin was produced as compared to the control and the stearins produced were purer and contained lesser amounts of unsaturated components. This has again proven that lesser olein entrainment occurred with the use of the additives. This result is similar to the findings of Kuriyama et al. (2011), in which olein yields can be improved by incorporating the additives into the process without compromising the olein quality.

\section{CONCLUSION}

This article studied the effect of the PGEmix- 8 additive on palm oil fractionation in relation to the yield and composition of the fractionation products. The study has shown that olein yield increased with the use of the additives. The TAG composition and FAC of olein were not affected, except for a slight increase in the total PUFA content. On the other 
(a) SFA content

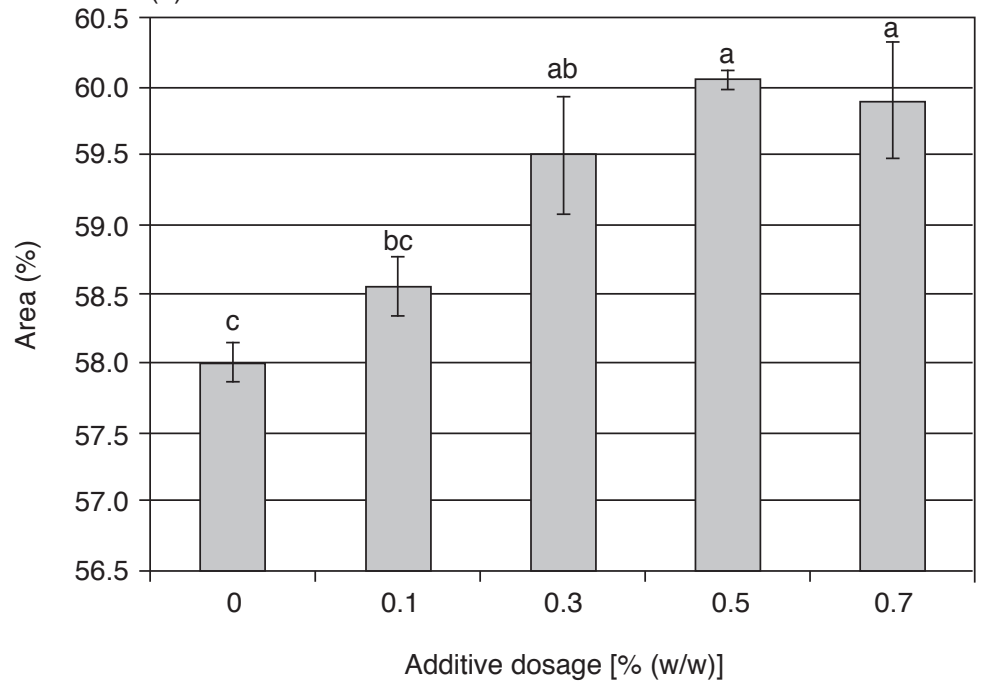

(b) MUFA content

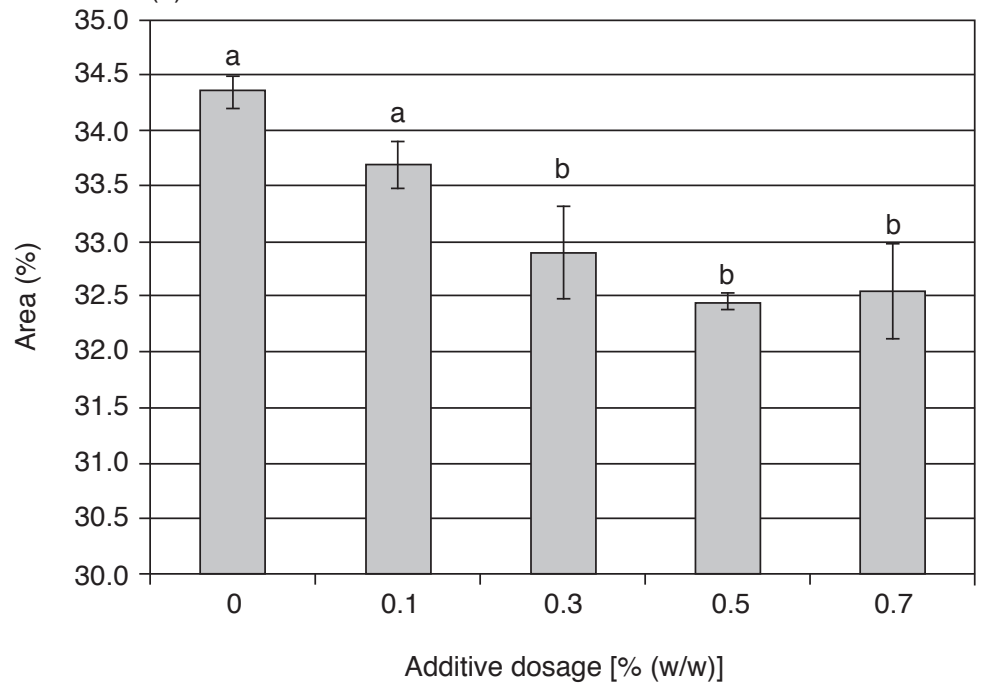

(c) PUFA content

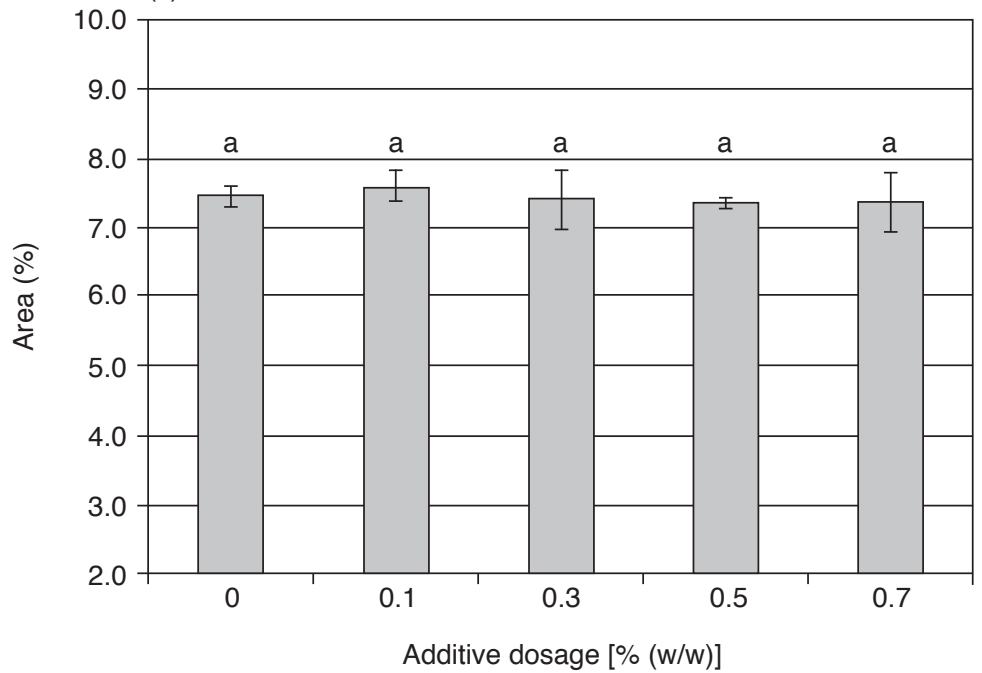

Note: Significance testing was conducted between different levels of PGEmix-8 dosage. Different letters indicate significant differences at $p<0.05$ according to Tukey's test.

Figure 5. Total (a) saturated fatty acid (SFA), (b) monounsaturated fatty acid (MUFA) and (c) polyunsaturated fatty acid (PUFA) contents in the stearin fractions with the use of polyglycerol ester additives (PGEmix-8) additives. 
hand, the total SFA content of stearin also increased with the addition of PGEmix- 8 additive. The crystal size distribution results before filtration showed that the distribution was shifted to the smaller size region when higher amounts of PGEmix-8 additive was used. Taken together, these results suggest that the increase in olein yield was a result of the lesser olein entrainment, which was caused by more effective filtration. This was due to the more homogeneous and smaller crystals of the palm oil slurries when PGEmix-8 was used.

\section{ACKNOWLEDGEMENT}

The authors would like to thank the Director-General of MPOB for permission to publish this article. The authors also thank Kuriyama Juhei from Sakamoto Yakuhin Kogyo Co. Ltd for providing PGEmix-8 additive for this study.

\section{REFERENCES}

Basso, R C; Ribeiro, A P B; Masuchi, M H; Gioielli, L A; Goncalves, L A G; Santos, A O D; Cardoso, L P and Grimaldi, R (2010). Tripalmitin and monoaclyglycerols as modifiers in the crystallisation of palm oil. Food Chem., 122: 1185-1192.

Deffense, E (1985). Fractionation of palm oil. J. Amer. Oil Chem. Soc., 62: 376-385.

De Oliveira, I F; Grimaldi, R and Goncalves, L A G (2014). Effect of diacylglycerols on crystallisation of palm oil (Elaeis guineensis). Eur. J. Lipid Sci. E Tech., 116: 904-909.

Ghazali, H M; Hamidah, S and Che Man, Y B (1995). Enzymatic transesterification of palm olein with nonspecific and 1,3-specific lipases. J. Amer. Oil Chem. Soc., 72: 633-639.

Gunstone, F D (2001). Procedures used for lipid modification. Structured and Modified Lipids (Gunstone, F D ed.). New York: Marcel Dekker. p. 11-35.

Hishamuddin, E; Stapley, A G F and Nagy, Z K (2011). Application of laser backscattering for monitoring of palm oil crystallisation from melt. J. Crystal Growth, 335: 172-180.

Hishamuddin, E and Omar, Z (2016). In situ characterisation of palm olein crystallisation behaviour by focused beam reflectance measurement (FBRM). J. Oil Palm Res. Vol. 28(1): 44-51.

Jacobsberg, B and Ho, O C (1976). Studies in palm oil crystallisation. J. Amer. Oil Chem. Soc., 53: 609-617.
Kellens, M; Gibon, V; Hendrix, M and Greyt, W D (2007). Palm oil fractionation. Eur. J. Lipid Sci. E Tech., 109: 336-349.

Kuriyama, J; Miyaji, Y; Tamura, K; Zaliha, O and Chong, C L (2011). Improved sustainable fractionation of palm oil using polyglycerol fatty acid esters. J. Oil Palm Res. Vol. 23: 1141-1145.

MPOB (2005). Methods of test for palm oil and palm oil products: Preparation of methyl esters of fatty acids. Part 4: Rapid method. MPOB Test Methods. MPOB, Bangi. p. 308-309.

Normah, I; Cheow, C S and Chong, C L (2013). Crystal habit during crystallisation of palm oil: Effect of time and temperature. Int. Food Res. J., 20: 417-422.

Saberi, A H; Lai, O M and Toro-Vázquez, J F (2011). Crystallisation kinetics of palm oil blends with palm-based diacylglycerol. Food Res. Int., 44: 425435.

Sato, K; Ueno, S and Yano, J (1999). Molecular interactions and kinetic properties of fats. Progress in Lipid Res., 38: 91-116.

Saitou, K; Taguchi, K; Homma, R; Shimizu, M; Yasunaga, K; Katsuragi, Y; Ueno, S and Sato, K (2017). Retardation mechanism of crystallisation of diaclylglycerols resulting from the addition of polyglycerol fatty acid esters. Crystal Growth $\mathcal{E}$ Design, 17: 4749-4756.

Saw, M H; Chong, C L and Yeoh, C B (2015). New developments in palm oil fractionation. Palm Oil Developments No. 62: 4-9.

Saw, M H; Hishamuddin, E; Chong, C L; Yeoh, C B and Lim, W H (2017). Effect of polyglycerol esters additive on palm oil crystallisation using focused beam reflectance measurement and differential scanning calorimetry. Food Chem., 214: 277-284.

Shimamura, K; Ueno, S, Miyamoto, Y and Sato, $K$ (2013). Effects of polyglycerine fatty acid esters having different fatty acid moieties and crystallisation of palm stearin. Crystal Growth $\mathcal{E}$ Design, 13: 4746-4754.

Smith, K W; Bhaggan, K; Talbot, G and Van Malssen, K F (2011). Crystallisation of fats: Influence of minor components and additives. J. Amer. Oil Chem. Soc., 88: 1085-1101.

Smith, K W and Sato, K (2018). Effects of foreign and indigenous minor components. Crystallisation of Lipids: Fundamentals and Applications in Food, 
Cosmetics, and Pharmaceuticals (Sato, K ed.). West Sussex: Wiley Blackwell. p. 263-281.

Swe, P Z; Che Man, Y B and Ghazali, H M (1995). Composition of crystal of palm olein formed at room temperature. J. Amer. Oil Chem. Soc., 72: 343-347.

Timms, R E (2005). Fractional crystallisation - The fat modification process for the $21^{\text {st }}$ century. Eur. J. Lipid Sci. E Tech., 107: 48-57.
Verstringe, S; Danthine, S; Blecker, C; Depypere, F and Dewettinck, K (2013). Influence of monopalmitin on the isothermal crystallisation mechanism of palm oil. Food Res. Int., 51: 344-353.

Verstringe, S; Dewettinck, K; Ueno, S and Sato, K (2014). Triacylglycerol crystal growth: Templating effects of partial glycerols studied with synchrotron radiation microbeam X-ray diffraction. Crystal Growth \& Design, 14: 5219-5226. 